\title{
Pancreatic cancer immunotherapy using a tumor lysate vaccine, engineered to express $\alpha$-gal epitopes, targets pancreatic cancer stem cells
}

\author{
TSUKASA TANIDA $^{1 *}$, MASAHIRO TANEMURA $^{1,3^{*}}$, EIJI MIYOSHI $^{2}$, HIROAKI NAGANO $^{1}$, \\ KENTA FURUKAWA $^{1}$, YUJI NONAKA ${ }^{2}$, HIROFUMI AKITA ${ }^{1}$, NAOKI HAMA ${ }^{1}$, HIROSHI WADA ${ }^{1}$, \\ KOICHI KAWAMOTO ${ }^{1}$, SHOGO KOBAYASHI ${ }^{1}$, HIDETOSHI EGUCHI ${ }^{1}$, MASAKI MORI ${ }^{1}$ and YUICHIRO DOKI $^{1}$
}

Departments of ${ }^{1}$ Gastroenterological Surgery and ${ }^{2}$ Molecular Biochemistry and Clinical Investigation, Osaka University Graduate School of Medicine, Suita, Osaka 565-0871; ${ }^{3}$ Department of Surgery, Osaka Police Hospital, Osaka 543-0035, Japan

Received August 13, 2014; Accepted September 16, 2014

DOI: $10.3892 /$ ijo.2014.2717

\begin{abstract}
Pancreatic cancer is a lethal disease that remains one of the most resistant to traditional therapies. Immunotherapy in pancreatic cancer induces the recruitment and activation of $\mathrm{T}$ cells that recognize tumor-associated antigens (TAAs); thus, the mechanism differs from that of chemotherapy and radiotherapy. The goal of cancer immunotherapy is to elicit immune responses against autologous tumors, and especially to induce multiple $\mathrm{T}$ cell clones against a variety of TAAs. In the present study, we prepared a polyvalent tumor lysate vaccine engineered to express the $\alpha$-gal epitopes, Gal $\alpha 1$ 3Gal $31-4$ GlcNAc-R (i.e., $\alpha$-gal tumor lysate), from primary tumors. The vaccine elicited strong antibody production against multiple TAAs in pancreatic cancer cells and induced activation of multiple tumor-specific $\mathrm{T}$ cells in $\alpha 1,3$-galactosyltransferase $(\alpha 1,3 \mathrm{GT})$ knockout $(\mathrm{KO})$ mice. The tumor lysate vaccine exhibited a similar effect on pancreatic cancer stem cells (CSCs) with the $\mathrm{CD} 44^{+} \mathrm{CD} 24^{+}$phenotype. Furthermore, in vivo experiments using NOD/SCID mice, inoculated with
\end{abstract}

Correspondence to: Dr Masahiro Tanemura, Department of Surgery, Osaka Police Hospital, 10-31 Kitayamacho Tennoujiku, Osaka 543-0035, Japan

E-mail: tanemuram@oph.gr.jp

*Contributed equally

Abbreviations: Ab, antibody; $\alpha 1,3 \mathrm{GT}, \alpha 1,3$-galactosyltransferase; $\alpha$-gal epitopes, Gal $\alpha 1-3$ Gal $\beta 1-4$ GlcNAc-R; anti-Gal, anti-Gal IgG antibody; APCs, antigen presenting cells; CSCs, cancer stem cells; CTLs, cytotoxic T lymphocytes; ELISA, enzyme-linked immunosorbent assay; ELISPOT, enzyme-linked immunospot; i.p., intraperitoneal; KO, knockout; mAb, monoclonal antibody; MUC1, mucin-1; NOD/SCID mice, non-obese diabetic/severe combined immunodeficiency mice; TAAs, tumor-associated antigens

Key words: pancreatic cancer, immunotherapy, cancer vaccine, cancer stem cells, $\alpha$-gal epitopes, $\alpha 1,3$-galactosyltransferase splenocytes from KO mice vaccinated with the $\alpha$-gal tumor lysate and injected with pancreatic cancer cells, showed successful induction of a marked immune response that resulted in suppression of tumorigenesis and significant improvement in overall survival. In contrast, inoculation of lymphocytes from KO mice vaccinated with control tumor lysate vaccine had no effects on tumor growth and survival. The results of both in vitro and in vivo experiments emphasize the efficiency of tumor lysate vaccines expressing $\alpha$-gal epitopes in targeting all pancreatic cancer cells, including differentiated cancer cells and pancreatic CSCs. The $\alpha$-gal tumor lysate vaccine could be the basis for a novel therapeutic approach in human clinical trials.

\section{Introduction}

Pancreatic cancer is one of the most aggressive types of cancer. With a 5 -year survival rate of $<5 \%$, it is the fourth most common cause of cancer-related deaths in the developed world (1). The reasons for the extremely poor prognosis are the late diagnosis, resistance to conventional chemotherapies, and high immunosuppression (2). Immunotherapy approaches designed to target tumor-associated antigens (TAAs) are promising treatments for pancreatic cancer. The major goal of immunotherapy is to activate $\mathrm{CD} 8^{+}$cytotoxic $\mathrm{T}$ lymphocytes (CTLs). Tumor-specific CTLs, activated by immunotherapy, are the effector cells most capable of directly recognizing and lysing cancer cells. However, immunotherapy alone is limited by the number of CTLs that can penetrate a large and established pancreatic tumor. To identify more efficient immunotherapies for pancreatic cancer, it is important to have an understanding of the following basic issues: i) the identity of tumor antigens and means to evaluate the immune response in pancreatic cancer; ii) mechanisms used by tumors to escape the immune system and strategies to overcome them; and iii) development of efficient immune interventions to eliminate pancreatic cancer cells. In particular, the identification of appropriate pancreatic cancer TAAs remains critical to the development of effective immunotherapy strategies and the assessment of tumor-specific CTL responses. Pancreatic 
cancer immunotherapies have targeted a few known proteins that were either the products of oncogenes (e.g., mutated Kras) (3) or differentially expressed glycoproteins such as MUC1, CEA (4), and mesothelin (5). However, vaccination against a single antigen has some disadvantages because it is unknown which of the identified antigens have the potential to induce an effective anti-tumor immune response. Furthermore, immunity against a single antigen may be ineffective in tumors with heterogeneous cell populations. In addition, the cellular environment in pancreatic cancer consists of not only cancer cells but also immune suppressive cells such as cancer-associated fibroblasts (CAFs), tolerogenic dendritic cells, myeloid-derived suppressor cells (MDCSs), immunosuppressive tumor-associated macrophages (TAMs), and T regulatory cells (6). These immunosuppressive cells inhibit the antitumor immunity induced by pancreatic cancer vaccines. The accumulation of these immunosuppressive cells in pancreatic cancer might be closely related to the extent of disease and fails to provide clinically relevant benefits (7).

Anti-Gal is the most abundant natural antibody in human sera from both normal subjects and patients with malignancies, and constitutes $\sim 1 \%$ of serum $\operatorname{IgG}(8)$. This antibody interacts specifically with the $\alpha$-gal epitopes on glycolipids and glycoproteins (8). Anti-Gal is produced primarily by anti-Gal B cells (i.e., B cells that can produce anti-Gal) present along the gastrointestinal tract due to continuous stimulation by bacteria of the natural flora (8). The $\alpha$-gal epitope is absent in humans but is synthesized by the glycosylation enzyme, $\alpha 1,3 \mathrm{GT}$, in very large amounts in cells from non-primate mammals, prosimians and New World monkeys (8). The $\alpha 1,3 \mathrm{GT}$ gene was inactivated as a pseudogene in ancestral Old World primates (8); thus, humans, apes, and Old World monkeys all lack $\alpha$-gal epitopes and instead produce anti-Gal in large amounts $(8,9)$. Introduction of cancer cells, or molecules such as TAAs and tumor lysates expressing $\alpha$-gal epitopes, into humans results in the binding of anti-Gal to these epitopes in vivo. This interaction is evident in xenotransplantation, in which in vivo binding of anti-Gal to $\alpha$-gal epitopes on transplanted pig hearts or kidneys is the main cause of hyperacute rejection of such grafts (9-11). This in situ interaction between anti-Gal/ $\alpha$-gal epitopes may be exploited for targeting cancer vaccines expressing $\alpha$-gal epitopes to antigen presenting cells (APCs).

In a recent study, we investigated the in vitro and in vivo effects of whole cell vaccination with $\alpha$-gal epitope-expressing pancreatic cancer cells (12). However, the effect was somewhat weak because melanoma cells transplanted in athymic mice formed tumors despite vaccination with $\alpha$-gal epitopes expressing pancreatic cancer cells. To further develop an effective immunotherapy for pancreatic cancer, we hypothesized that tumor lysate is a more suitable source of TAAs because it contains several known and unknown antigens in cancer cells and stromal cells that can elicit a broad spectrum anti-tumor immune response. Moreover, the primary tumor of pancreatic adenocarcinoma contains a subset of pancreatic cancer cells with stem cell properties (i.e., pancreatic cancer stem cells: pancreatic CSCs) $(13,14)$. These pancreatic CSCs, whose phenotypic identification is still a matter of debate, could have different biologically important characteristics, such as the capacity to self-renew and divide asymmetrically $(13,14)$.
In pancreatic cancer, recent data suggest that the presence of these putative CSCs in primary tumors is associated with shorter overall survival, resistance to the standard cytotoxic agent gemcitabine and enhanced metastatic potential $(13,14)$. However, it is noteworthy that the induction of the immune response against pancreatic CSCs by standard vaccination with tumor lysate, as described above, is often difficult because the CSCs constitute only $1 \%$ of all cancer cells $(13,14)$. Accordingly, it is desirable to prepare a vaccine from lysates of tumors engineered to express $\alpha$-gal epitopes to increase the immunogenicity of the broad-spectrum of TAAs present in both differentiated pancreatic cancer cells and pancreatic CSCs.

In the present study, we investigated the effects of vaccination with lysate from $\alpha$-gal epitope-expressing tumors, using adoptive transfer mouse models. The tumor growth of pancreatic cancer cells, which include differentiated pancreatic cancer cells and pancreatic CSCs, in NOD/SCID mice was examined as well as the survival of recipients. Furthermore, the immunoresponses of both $\mathrm{B}$ and $\mathrm{T}$ cells were investigated in details.

\section{Materials and methods}

Ethics statement. All animals were bred and maintained as specific pathogen-free condition (SPF) at the Institute of Experimental Animal Sciences, Osaka University Medical School. All animal care and procedures described in the present study were approved by the Ethics Review Committee for Animal Experimentation of Osaka University (experimental number 20-055-0), and animal wellbeing was taken into consideration in the study design. All animal experiments were performed in accordance with the Guidelines for proper conduct for animal experiments from Scientific Council of Japan.

Mice. Mice used in the present study had disrupted $\alpha 1,3-$ galactosyltransferase $(\alpha 1,3 \mathrm{GT})$ genes and are referred as $\alpha 1,3 \mathrm{GT}$ knockout (KO) mice. The $\alpha 1,3 \mathrm{GT} \mathrm{KO}$ mice were generated on a $\mathrm{C} 57 \mathrm{BL} / 6 \times \mathrm{BALB} / \mathrm{c}$ genetic background (H-2bxd) $(15,16)$. Prior to the experimental procedure, antiGal antibody $(\mathrm{Ab})$ production was elicited in 6- to 8-week-old $\alpha 1,3$ GT KO mice by four weekly intraperitoneal (i.p.) injections with $100 \mathrm{mg}$ of pig kidney membrane homogenate (9). The amount (titer) of anti-Gal Ab was confirmed to be similar to that observed in humans (1:400-1:2,000, designated as high anti-Gal KO mice) by enzyme-linked immunosorbent assay (ELISA) with synthetic $\alpha$-gal epitopes linked to bovine serum albumin (BSA) (Dextra Laboratories Ltd., Berkshire, UK) as the solid phase antigen $(9,12,15)$.

Preparation of tumor lysate vaccines expressing $\alpha$-gal epitopes. The human pancreatic cancer cell line, PANC1 (ATCC, Manassas, VA, USA), which intrinsically expressed the Mucin1 (MUC1) molecule, was employed $(12,17)$. We established stable PANC1-transfected cells, expressing $\alpha$-gal epitopes, by mouse $\alpha 1,3 \mathrm{GT}$ gene transfection (called $\alpha$-gal PANC1) as previously described (12). To generate PANC1 tumors, $2 \times 10^{6}$ live cells (either parental or $\alpha$-gal PANC1) were injected subcutaneously into the back of non-obese 

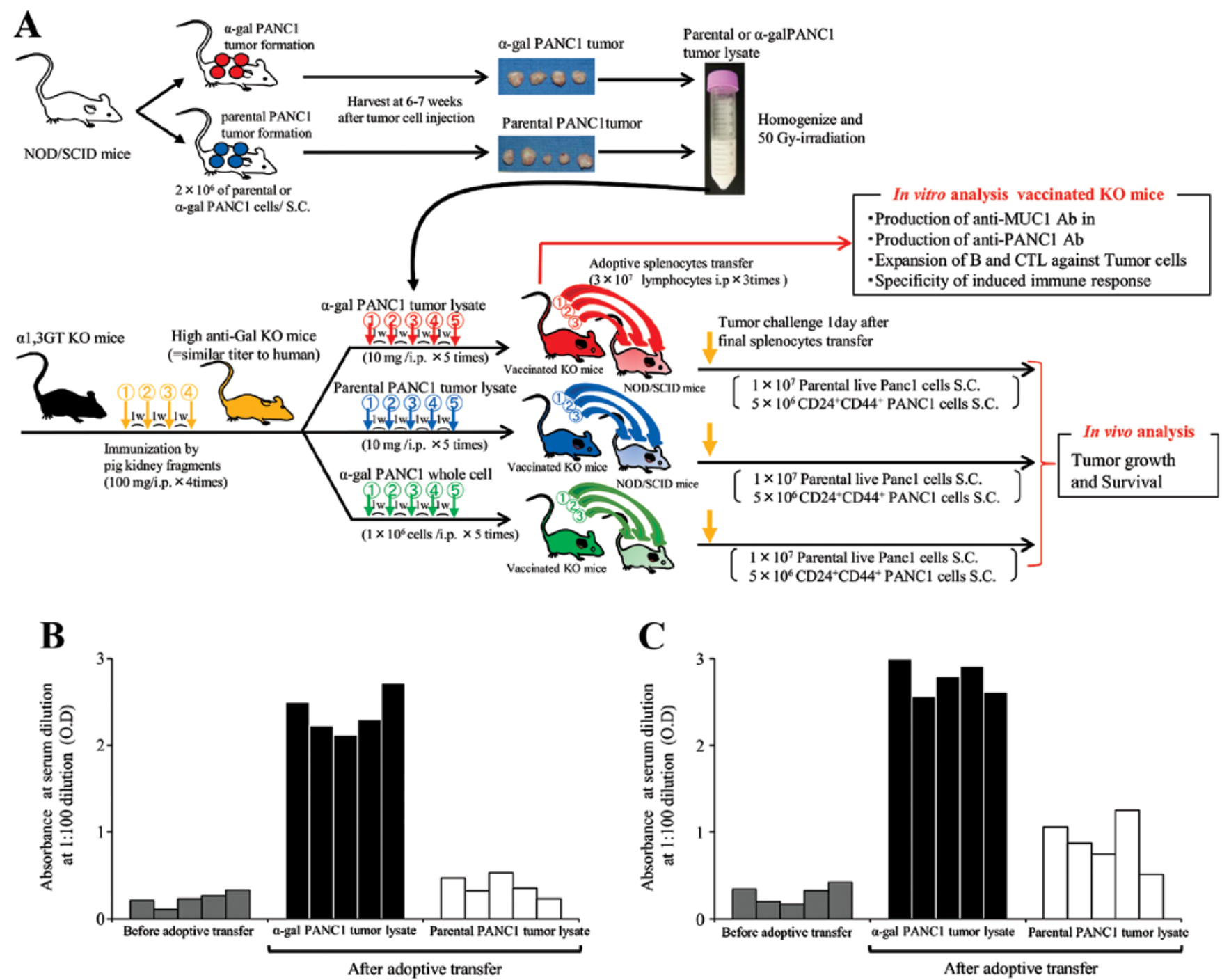

Figure 1. The experimental design. (A) Experimental design of in vivo studies. (B) Production of anti-MUC1 IgG in adoptive transferred NOD/SCID mice, assessed by ELISA. (C) Production of anti-PANC1 IgG in adoptive transferred NOD/SCID mice, assessed by ELISA. Data represent either anti-MUC1 or anti-PANC1 IgG activities in five representative mice for each group of ten with similar results.

diabetic severe combined immunodeficiency (NOD/SCID) mice (NOD. CB17-Prkdc scid/J mice; Charles River, Tokyo Japan). The grown PANC1 tumors were enucleated and homogenized under sterile conditions, washed with $200 \mathrm{ml}$ of PBS and centrifuged at 30,000 x g. The tumor membranes were resuspended at $100 \mathrm{mg} / \mathrm{ml}$ (weight/volume) in saline, and were subsequently irradiated with $50 \mathrm{~Gy}$ and frozen until needed (Fig. 1A).

Tumor lysate vaccination. The high anti-Gal KO mice were vaccinated by i.p. injection five times at 1-week intervals with $10 \mathrm{mg}$ of 50-Gy-irradiated parental or $\alpha$-gal PANC1 tumor lysates (abbreviated here as pt-lysate or $\alpha$-gal-t-lysate, respectively). One week after the 5th vaccination, the mice were assessed for immune response induced by tumor lysate vaccination as described below (Fig. 1A). To compare the effectiveness of the $\alpha$-gal PANC1 whole cell (abbreviated here as $\alpha$-gal-whole-c) vaccine with that of $\alpha$-gal-t-lysate vaccine, the mice received five i.p. injections of $1 \times 10^{6}$ cells of 50 Gy-irradiated $\alpha$-gal PANC1 whole cell vaccine in a manner similar to the tumor lysate vaccine (Fig. 1A) (12).
Enzyme-linked immunosorbent assay (ELISA). To determine whether the studied tumor lysates expressed $\alpha$-gal epitopes, the tumor homogenates were assayed by ELISA using the monoclonal anti-Gal IgM Ab, M86, as previously described (17-19). The expression level of MUC1 in tumor lysates was assessed by ELISA using anti-MUC1 monoclonal antibody (mAb) (clone VU4H5; Santa Cruz Biotechnology, Santa Cruz, CA, USA; cat. no. sc-7313, lot no. B1611). Anti-MUC1 IgG production, was detected by ELISA using MUC1-BSA as the solid phase antigen, as previously described (12). Anti-PANC1 IgG production was detected by ELISA using dried-up PANC1 cells as the solid phase antigen, as previously described (20).

Enzyme-linked immunospot analysis (ELISPOT). An enzymelinked immunospot (ELISPOT) assay was used to identify the expansion of anti-MUC1 secreting B cells and MUC1-specific activated $\mathrm{T}$ cells (i.e., IFN- $\gamma$ secreting $\mathrm{T}$ cells), using a previously described method (12).

Immunohistochemical analysis and immunofluorescence microscopy. Parental PANC1 and $\alpha$-gal PANC1 tumor 
specimens, generated in NOD/SCID mice, were cut into small blocks, fixed in formalin and then embedded in paraffin. Tissue sections ( $4 \mu \mathrm{m}$ thick) were incubated with either mouse anti-human MUC1 mAb (1:100; Santa Cruz Biotechnology; clone VU4H5, cat. no. sc-7313, lot. no. B1611) or M86 anti-Gal $\mathrm{mAb}(1: 2)(21)$ in PBS Tween-20 (0.05\% w/v) for $16 \mathrm{~h}$ at $4^{\circ} \mathrm{C}$. The sections were then incubated with appropriate antibodies (for anti-MUC1 Ab, HRP-conjugated goat anti-mouse IgG, dilution 1:1,000; for M86 mAb, HRP-conjugated goat antimouse IgM, dilution 1:1,000). Immunostaining was visualized with $0.02 \%$ diaminobenzidine (DAB; Sigma-Aldrich) as the chromogen. The specificity of the primary Abs was verified using control sections prepared as described above but without the use of the primary Abs.

To evaluate the expression of CD44 and CD24, which are CSC markers of pancreatic cancer, on parental and $\alpha$-gal PANC1 tumors, tissue sections were incubated with either rabbit anti-human CD44 mAb (dilution 1:100; Abcam, Cambridge, MA, USA; cat. no. ab97478) or rabbit anti-human CD24 mAb (dilution 1:100, Santa Cruz Biotechnology; cat. no. FL-80, sc-11406), respectively, followed by incubation with Alexa Fluor 555 goat anti-rabbit IgG Ab (A21429, dilution 1:1,000; Invitrogen). Fluorescence signals were observed with a Biozero fluorescence microscope (Keyence Corporation of America, Elmwood Park, NJ, USA). The $\alpha$-gal epitopes in PANC1 tumors were detected by incubating the sections with M86 anti-Gal mAb (1:2 dilution) (21) in PBS Tween-20 for $16 \mathrm{~h}$ at $4^{\circ} \mathrm{C}$, followed by incubation with Alexa Fluor 488 goat anti-mouse $\operatorname{IgM} \mathrm{Ab}$ (A21042; dilution 1:1,000; Invitrogen). Fluorescence signals were assessed by fluorescence microscopy.

Flow cytometric analysis. To investigate Ab production against differentiated pancreatic cancer cells (isolated differentiated cancer cells from PANC1 cells; i.e., CD44-CD24- PANC1 cells) and pancreatic CSCs (isolated cancer stem cells from PANC1 cells; i.e., $\mathrm{CD} 44^{+} \mathrm{CD} 24^{+} \mathrm{PANC} 1$ cells), cells were stained with sera from $\mathrm{KO}$ mice vaccinated with pt-lysate, $\alpha$-gal-t-lysate, or $\alpha$-gal-whole-c, as previously described (12). To determine whether or not splenocytes from the vaccinated $\alpha 1,3 \mathrm{GT} \mathrm{KO}$ mice can be specifically stimulated by $\mathrm{MUC1}$ peptide, PANC1 cells or PANC1 tumor lysate, a carboxyfluorescein diacetate succinimidyl ester (CFSE; Invitrogen, Carlsbad, CA, USA; CellTrace $^{\mathrm{TM}}$ CFSE Cell Proliferation kit, cat. no. C34554) assay was performed according to the manufacturer's recommended protocol. Human embryonic kidney HEK293 cells were also employed as stimulatory cells. The CFSE labeled mouse splenocytes were cultured in 96-well round bottom plates (cat. no 3870-096; Iwaki, Japan) at $2 \times 10^{5}$ cells/well with $1 \times 10^{4}$ stimulatory cells (irradiated PANC1 or HEK293 cells), and $10 \mu \mathrm{g} /$ well of MUC1 peptide, $10 \mathrm{mg} /$ well of PANC1 tumor lysate or $3 \mu \mathrm{g} / \mathrm{ml}$ of ConA. The stimulated cells were cultured for $72 \mathrm{~h}$. Proliferation of either $\mathrm{CD}^{+}$or $\mathrm{CD}^{+}$responder T-cells was measured with a FACSCalibur and analyzed with CellQuest software (BD Biosciences).

In vivo studies of the tumor lysate vaccine. As shown in Fig. 1A, high anti-Gal KO mice $(n=90)$ were generated by immunization with pig kidney fragments, then vaccinated with pt-lysate $(n=30), \alpha$-gal-t-lysate $(n=30)$ or $\alpha$-gal-whole-c $(n=30)$. One week after the last vaccination, splenocytes were prepared from successfully vaccinated donor $\mathrm{KO}$ mice and then suspended in warm $\left(37^{\circ} \mathrm{C}\right)$, sterile RPMI complete medium containing $50 \mu \mathrm{M}$ of 2-mercaptoethanol. For adoptive transfer, these isolated splenocytes were transferred by i.p. injection into NOD/SCID mice three times at 3-day intervals (75-150× $10^{6}$ cells/vaccinated KO mouse). Splenocytes obtained from pt-lysate-, $\alpha$-gal-t-lysate- or $\alpha$-gal-whole-c-vaccinated $\mathrm{KO}$ mice were injected in equal amounts into NOD/SCID recipient mice (in total, $90 \times 10^{6}$ splenocytes were transferred; each group, $n=10$ transferred NOD/SCID mice). One day after adoptive transfer, all NOD/SCID mice were challenged with subcutaneous injection of either $10 \times 10^{6}$ live PANC1 cells or $5 \times 10^{6} \mathrm{CD} 44^{+} \mathrm{CD} 24^{+} \mathrm{PANC} 1$ cells (i.e., the pancreatic CSC fraction of PANC1 cells) (14). Subsequently, these mice were examined for both tumor growth and survival. All mice were monitored every day after injection to detect the changes of general signs. Mice were sacrificed at the humane endpoints defined as following changes: i) physical appearance (selfinjury, soiling of hair with urine of faces, bleeding, severe body weight loss defined by $>20 \%$ loss in maximal body weight and loss of appetite); ii) clinical physiology (tachypnea and low body temperature). When remarkable increase of tumor size, defined by $>10 \%$ increase in body weight was observed, mice were humanely sacrificed. The mice were induced deep anesthesia by isoflurane and subsequently sacrificed by cervical dislocation.

Statistical analysis. Data were collected from at least five independent experiments. Quantitative data were expressed as the mean \pm SD. Statistical analysis was performed using the Student's t-test. Kaplan-Meier curves of estimated survival were generated, and comparisons between parental PANC1 tumor lysate, $\alpha$-gal PANC1 tumor lysate, and $\alpha$-gal PANC1 whole cell vaccine groups were performed using a two-sided log rank test. A P-value $<0.05$ was considered significant.

\section{Results}

Generation of a tumor lysate vaccine expressing $\alpha$-gal epitopes. The histological findings of the PANC1 tumors originating from parental and $\alpha$-gal PANC1 cells were compatible with those of human pancreatic cancer (Fig. 2A). Low expression levels of $\alpha$-gal epitopes were observed in the parental PANC1 tumor, whereas high expression levels were detected on the cell surface of $\alpha$-gal PANC1 tumors (Fig. 2A). The low expression of $\alpha$-gal epitopes in parental PANC1 tumor was likely dependent on the migration of stromal tissues, including vascular and fibrous cells that originated from recipient NOD/SCID mice.

We previously reported the expression of $5 \times 10^{13} \alpha$-gal epitopes/mg-lysate in pig kidney fragments $(9,19)$. ELISA determined that approximately $2 \times 10^{14} \alpha$-gal epitopes/mg-lysate were expressed in $\alpha$-gal-t-lysate (Fig. 2B). For $\alpha$-gal-whole-c, similar levels of $\alpha$-gal epitope expression were detected $\left(\sim 2 \times 10^{9}\right.$ $\alpha$-gal epitopes/cell). A BCA protein assay was performed to assess the accurate protein concentration of tumor lysates or $\alpha$-gal-whole-c. The protein concentration was approximately $1 \mathrm{mg} / \mathrm{ml}$ for both tumor lysates and $\alpha$-gal-whole-c. Therefore, $100 \mathrm{mg}$ of glycoprotein/i.p. injection, expressing $2 \times 10^{15} \alpha$-gal epitopes, was contained in either the $10 \mathrm{mg} \alpha$-gal-t-lysate or 

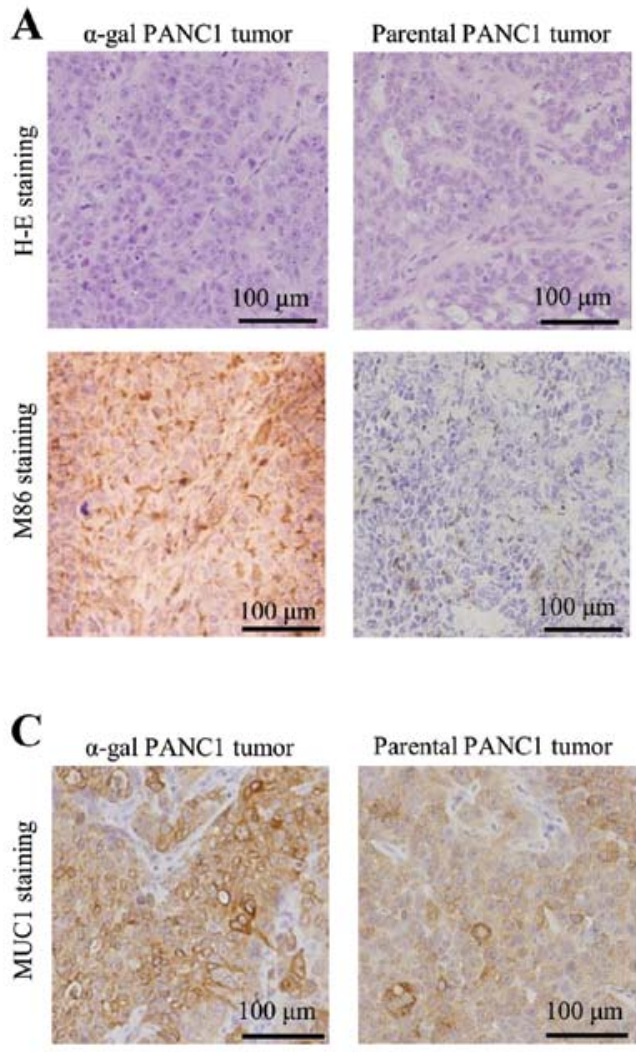
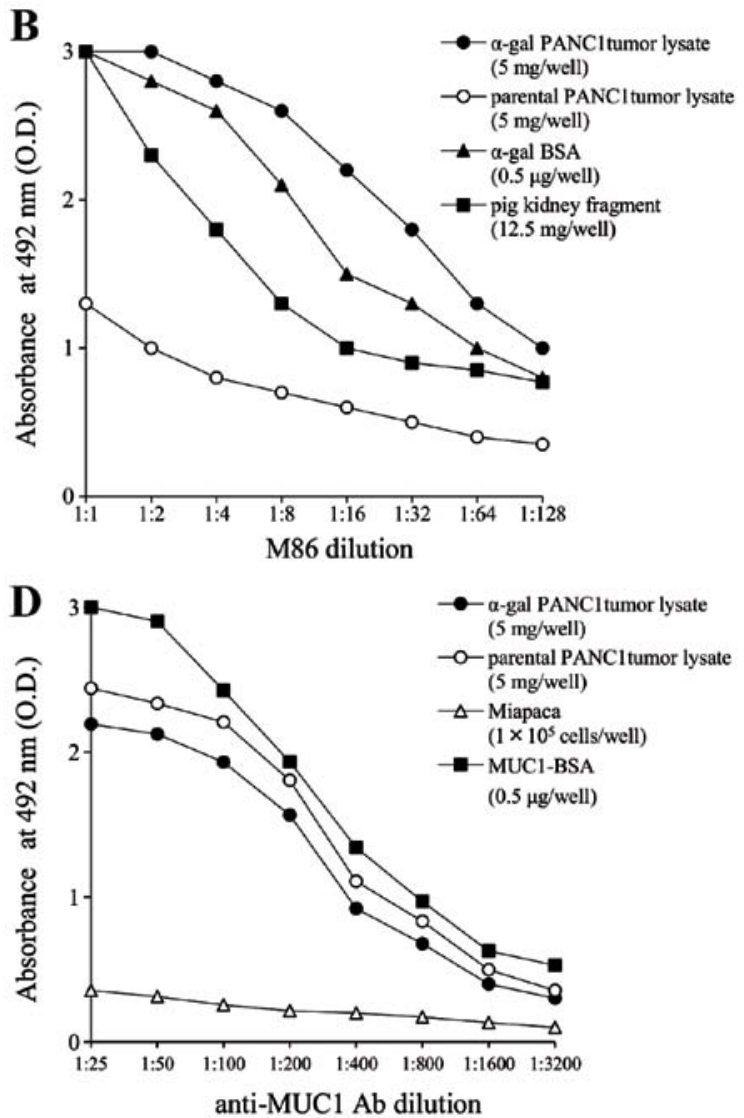

Figure 2. The expression levels of $\alpha$-gal epitopes and MUC1 on parental PANC1 and $\alpha$-gal PANC1 tumors. (A) Images of $\alpha$-gal PANC1 and parental PANC1 tumors stained with hematoxylin-eosin and M86 mAb. (B) Expression levels of $\alpha$-gal epitopes in tumor lysates assessed by ELISA using M86 mAb. (C) Images of $\alpha$-gal PANC1 and parental PANC1 tumors stained with anti-MUC1 mAb. (D) Expression levels of the MUC1 molecule in tumor lysates assessed by ELISA, using anti-MUC1 mAb.

$1 \times 10^{6} \alpha$-gal-whole-c vaccination given to high anti-Gal KO mice. Similar levels of MUC1 expression were observed in parental and $\alpha$-gal PANC1 tumors by both immunohistochemical staining and ELISA (Fig. 2C and D). Similar levels of MUC1 expression were also observed in $\alpha$-gal-whole-c (data not shown).

Vaccination with $\alpha$-gal PANCl tumor lysate induces an effective antitumor immune response of both $B$ - and $T$-cells. As shown in Fig. 3 (A and B; anti-PANC1 IgG response, C and D; anti-MUC1 IgG response), repeated vaccinations (five times) with $10 \mathrm{mg} / \mathrm{i} . \mathrm{p}$. injection of $\alpha$-gal-t-lysate elicited strong responses of anti-PANC1 IgG and anti-MUC1 IgG. Vaccinations with pt-lysate did not induce these $\mathrm{Ab}$ responses. Vaccination with the $\alpha$-gal-t-lysate elicited an $\sim 16$-fold increase in both anti-PANC1 IgG and anti-MUC1 IgG production, compared with the pt-lysate vaccination. There was $\sim 2-4$-fold higher production of anti-PANC1 IgG observed in sera from $\alpha$-gal-t-lysate vaccinated $\mathrm{KO}$ mice than detected after vaccination with $\alpha$-gal-whole-c; however, there were no differences in anti-MUC1 IgG production (data not shown).

To further investigate the subclass of immunoglobulin reactivity of either anti-PANC1 IgG or anti-MUC1 IgG, we performed an ELISA using HRP-conjugated goat anti-mouse IgG1, IgG2a, IgG2b and IgG3 mAbs as secondary antibodies. All secondary antibodies were purchased from Bethyl Laboratories Inc. Sera from $\alpha$-gal-t-lysate-vaccinated KO mice showed large amounts of all IgG subclasses, including IgG1, IgG2b, IgG2a and IgG3. The IgG1 subclass of both anti-PANC1 and anti-MUC1 IgG was especially expressed, and induces strong antitumoral cytolysis through antibody-dependent cellmediated cytotoxicity and complement-dependent cytotoxicity (Fig. 4A and C). On the other hand, sera from pt-lysatevaccinated $\mathrm{KO}$ mice produced only a small amount of IgG1 and did not produce the IgG2a, IgG2b and IgG3 subclasses (Fig. 4B and D). With the $\alpha$-gal-whole-c vaccination, there was no production of the IgG2a subclass of either anti-PANC1 or anti-MUC1 IgG in sera despite production of large amounts of the other IgG subclasses (data not shown) (12).

As shown in Fig. 5A, splenocytes isolated from pt-lysatevaccinated $\mathrm{KO}$ mice displayed $136.7 \pm 13.2$ spots $/ 1 \times 10^{6}$ splenocytes of anti-MUC1-secreting B cells. In contrast, $\alpha$-gal-t-lysate-vaccinated KO mice had $305.3 \pm 44.0$ spots $/ 1 \times 10^{6}$ splenocytes $(\mathrm{P}=0.0071)$. In pt-lysate-vaccinated KO mice, we detected $181.7 \pm 27.5$ and $44.3 \pm 6.5$ spots of IFN- $\gamma$ secreting $\mathrm{T}$ cells in the presence and absence of the MUC1 stimulator peptide, respectively; thus, a significant increase in the number of spots was observed with MUC1 peptide stimulation ( $\mathrm{P}=0.0011$; Fig. 5B). In $\alpha$-gal-t-lysate-vaccinated $\alpha 1,3 \mathrm{GT}$ KO mice, $626.7 \pm 118.6$ and $76.3 \pm 12.9$ spots were detected with or without MUC1 peptide stimulation, respectively, and the difference in the number of spots was also significant $(\mathrm{P}=0.0013$; Fig. 5B). Furthermore, the number of spots in the presence of the MUC1 peptide was significantly higher in the 

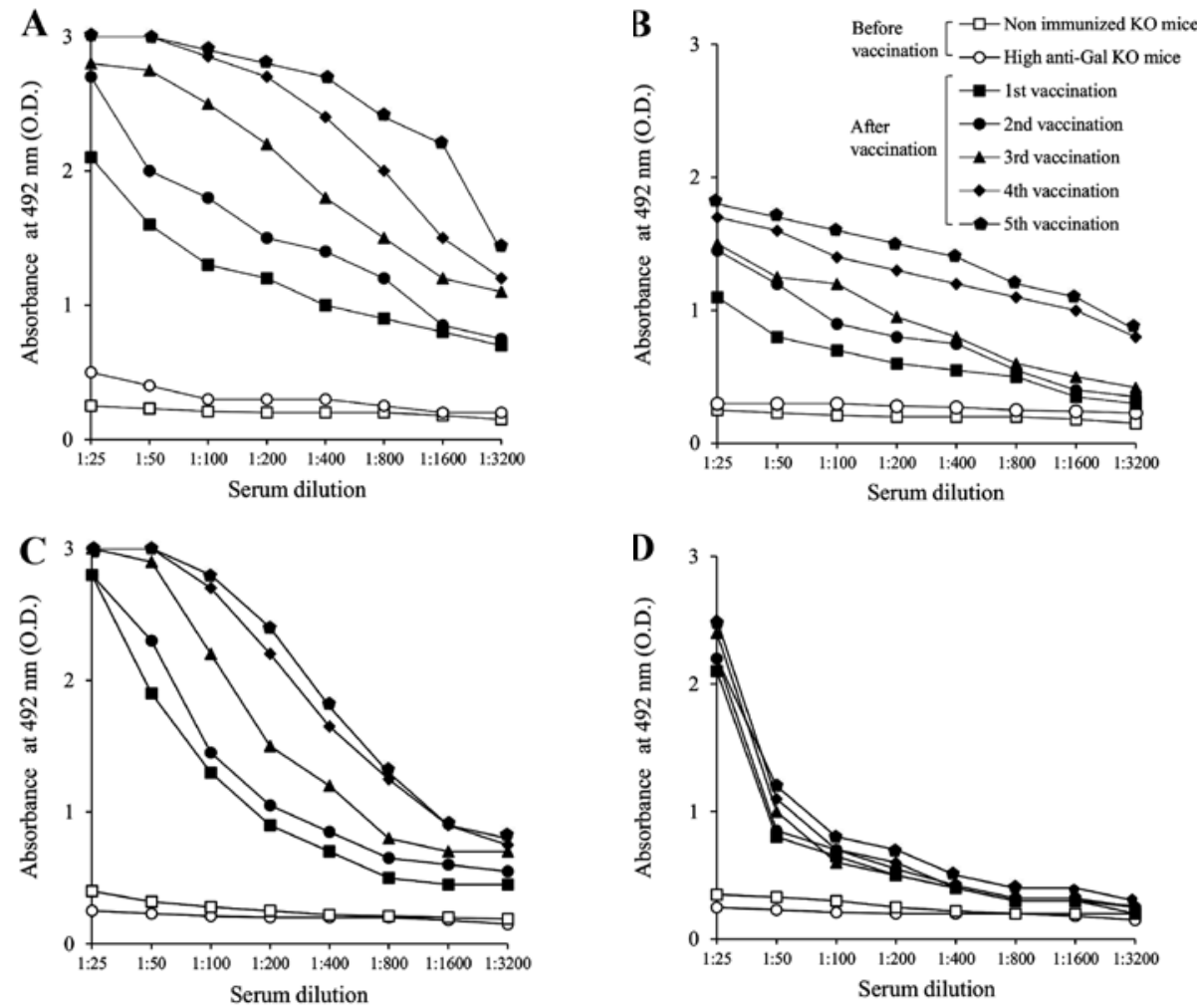

Figure 3. Anti-PANC1 IgG and anti-MUC1 IgG production induced by tumor lysate vaccination. (A and B) Anti-PANC1 IgG production in high anti-Gal KO mice vaccinated with (A) $\alpha$-gal PANC1 tumor lysate and (B) parental PANC1 tumor lysate. (C and D) Anti-MUC1 IgG production in high anti-Gal KO mice vaccinated with (C) $\alpha$-gal PANC1 tumor lysate and (D) parental PANC1 tumor lysate. Representative data are shown from five experiments with similar results. ELISA results represent one data set from a group of five mice.
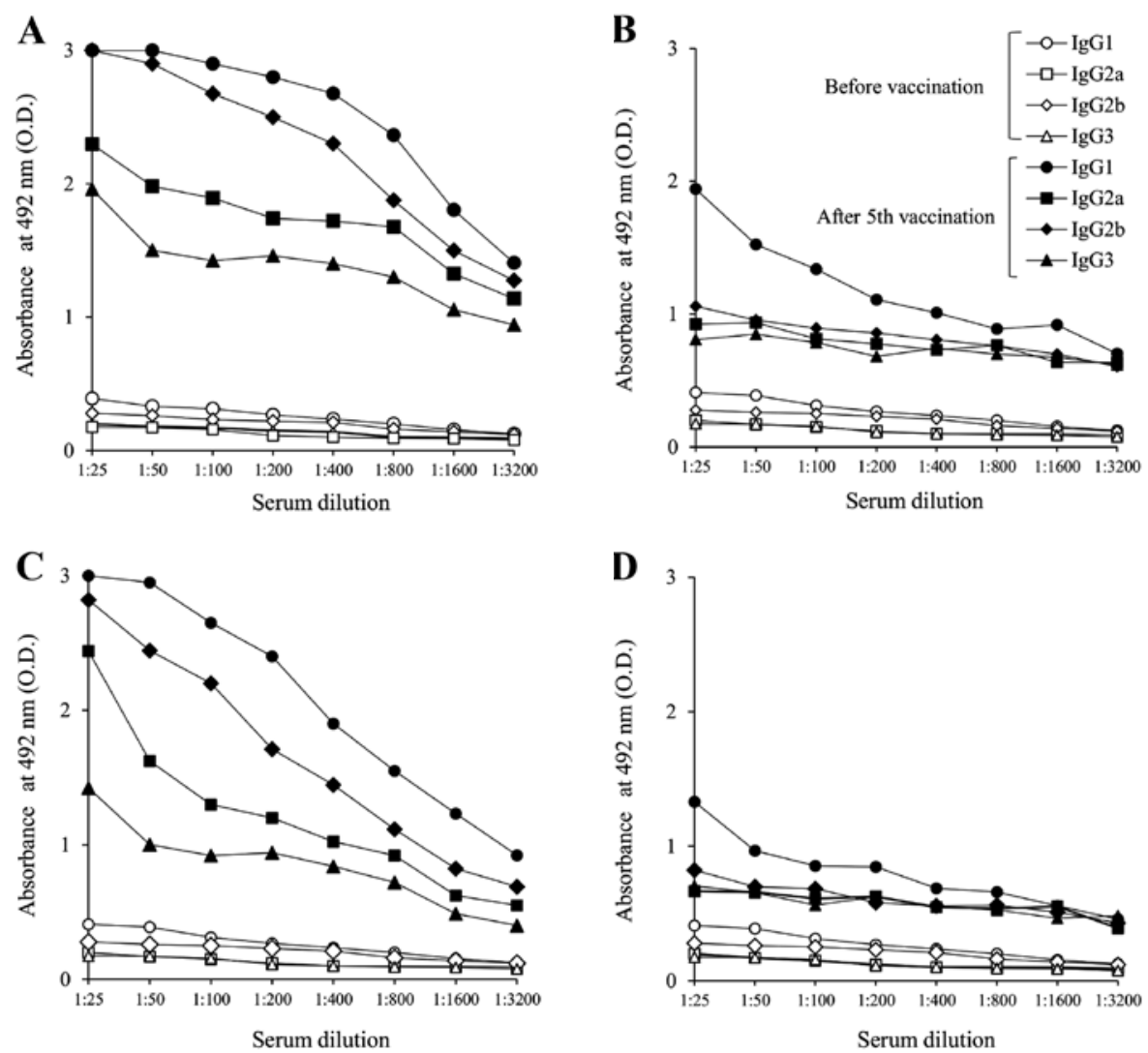

Figure 4. Subclasses of induced anti-PANC1 IgG and anti-MUC1 IgG in high anti-Gal KO mice. (A) Subclasses of induced anti-PANC1 IgG in the $\alpha$-gal PANC1 tumor lysate vaccination group. (B) Subclasses of induced anti-PANC1 IgG in the parental PANC1 tumor lysate group. (C) Subclasses of induced anti-MUC1 IgG in the $\alpha$-gal PANC1 tumor lysate group. (D) Subclasses of induced anti-MUC1 IgG in the parental PANC1 tumor lysate group. Representative data are shown from five experiments with similar results. ELISA results represent one data set from a group of five mice. 

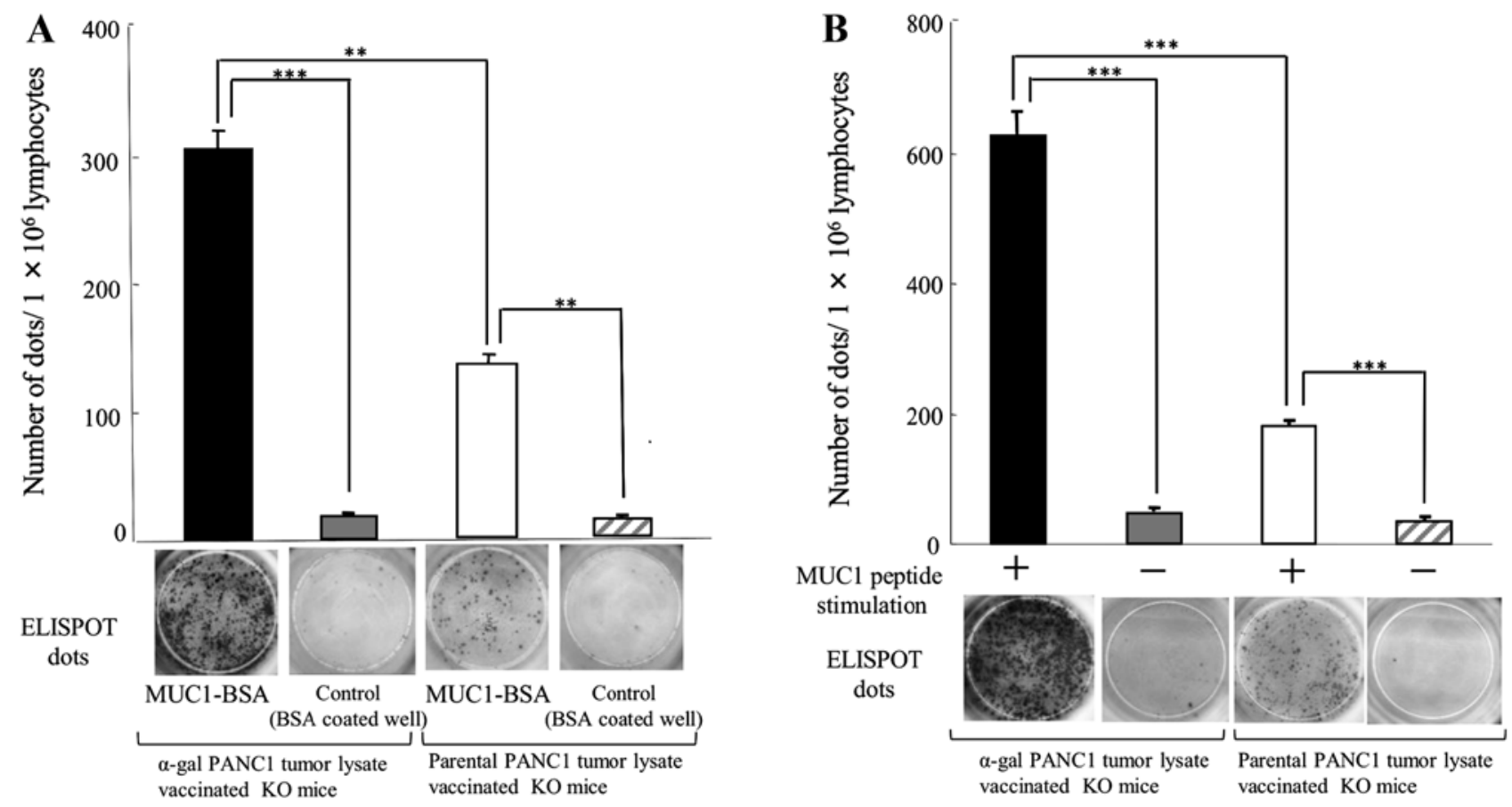

Figure 5. The expansion of B and T cells in response to tumor lysate vaccination. ELISPOT assay for (A) anti-MUC1 Ab-producing B cells and (B) MUC1 specific activated T cells, detected as IFN- $\gamma$ secreting lymphocytes. Data represent the mean \pm SD of five independent splenocyte preparations; bars, SD. Statistical analyses were performed by the Student's t-test; ${ }^{* *} \mathrm{P}<0.01,{ }^{* * *} \mathrm{P}<0.005$.

$\alpha$-gal-t-lysate-vaccinated group than in the pt-lysate group $(\mathrm{P}=0.0032$; Fig. 5B).

Immune response in $\alpha$-gal PANCl tumor lysate-vaccinated $\alpha 1,3 G T$ KO mice is specific against MUC1 peptide, PANC1 cells and PANC1 tumor lysate. As shown in Fig. 6, the negative control showed no significant difference in the percentage of proliferated T cells, which appeared as CFSE-low responder $\mathrm{T}$ cells (i.e., the CFSE intensity was $<400$ ), between $\alpha$-gal-t- and pt-lysate-vaccination. The positive control (Concanavalin A stimulation) also showed no significant differences in proliferated T cells. Proliferation of T cells was significantly induced in the presence of PANC1 whole cells, PANC1 tumor lysate and MUC1 peptide; whereas, no proliferation was elicited by HEK293 whole cell stimulation. Lymphocytes were also stimulated with other kinds of irradiated cells, including monkey COS7 cells and mice fibroblast NIH3T3 cells. However, these types of stimulatory cells failed to induce significant proliferation (data not shown). Moreover, the proliferation rate of $\mathrm{T}$ cells in $\alpha$-gal-t-lysate-vaccinated $\alpha 1,3 \mathrm{GT}$ KO mice was significantly higher than in pt-lysate-vaccinated $\alpha 1,3 \mathrm{GT} \mathrm{KO}$ mice (Fig. 6).

Adoptive transfer of splenocytes from $\alpha$-gal PANC1 tumor lysate-vaccinated $\alpha 1,3 G T$ KO mice induces an effective anti-tumor response in NOD/SCID mice. The experimental design of in vivo studies is shown in Fig. 1A. To confirm the production of anti-PANC1 and anti-MUC1 IgG Abs in adoptively transferred NOD/SCID mice, we performed an ELISA prior to tumor challenge (Fig. 1B and C). Sera from control NOD/SCID mice (without adoptive transfer of splenocytes) showed no anti-PANC1 and anti-MUC1 IgG Ab production; while, NOD/SCID mice who received pt-lysate-vaccinated splenocytes showed small amounts of anti-PANC1 IgG Ab
(Fig. 1B and C). In contrast, extremely large amounts of both anti-PANC1 and anti-MUC1 IgG Abs were noted in NOD/SCID mice who received $\alpha$-gal-t-lysate-vaccinatedsplenocytes (Fig. 1B and C). Representative pictures of mice treated with $\alpha$-gal-whole-c, $\alpha$-gal-t-lysate or pt-lysate are shown in Fig. 7A. Compared with untreated control mice (data not shown), pt-lysate- and $\alpha$-gal-whole-c-vaccinated mice developed large tumors; while, no tumors were noted in the $\alpha$-gal-t-lysate-vaccinated mice (Fig. 7A and B). The in vivo results, including survival time, are summarized in Table I. As shown in Fig. 7B, we monitored tumor growth in splenocyte-transferred mice. No significant differences in the time to appearance of palpable tumor after tumor challenge were observed in either the untreated control or pt-lysate group (untreated, 10.6 \pm 2.5 days; pt-lysate, $11.9 \pm 2.1$ days). In contrast, the development of tumors in the $\alpha$-gal-whole-c-vaccination group was significantly delayed compared with the untreated and pt-lysate groups ( $\alpha$-gal-whole-c: $16.0 \pm 2.8$ days, $\mathrm{P}=0.018$ vs. control; $\mathrm{P}=0.004$ vs. pt-lysate). In the untreated control group, the maximum tumor size was $100 \mathrm{~mm}^{2}$ within 29 to 34 days (mean, 31.4 \pm 2.1 days). In comparison, tumor growth to a similar size was markedly delayed in both the pt-lysate group (40.3 \pm 6.9 days, $\mathrm{P}=0.007$ vs. control) and $\alpha$-gal-whole-c group ( $45.6 \pm 8.3$ days, $\mathrm{P}=0.0013$ vs. control). The beneficial effects of vaccination with pt-lysate, $\alpha$-gal-t-lysate, or $\alpha$-galwhole-c were also noted in the prolongation of survival after tumor challenge (Fig. 7C). As shown in Fig. 7C and Table I, the mean survival time of KO mice vaccinated with $\alpha$-gal-t-lysate was markedly prolonged $(82.5 \pm 21.9$ days $)$ compared with non-vaccinated $(41.0 \pm 5.7$ days, $\mathrm{P}<0.001)$, pt-lysate-vaccinated (48.0 \pm 6.7 days, $\mathrm{P}<0.001)$, and $\alpha$-gal-whole-c-vaccinated $\mathrm{KO}$ mice $(57.0 \pm 12.6$ days, $\mathrm{P}=0.01)$. The final cause of death for adoptively transferred NOD/SCID mice from non-vaccinated, 


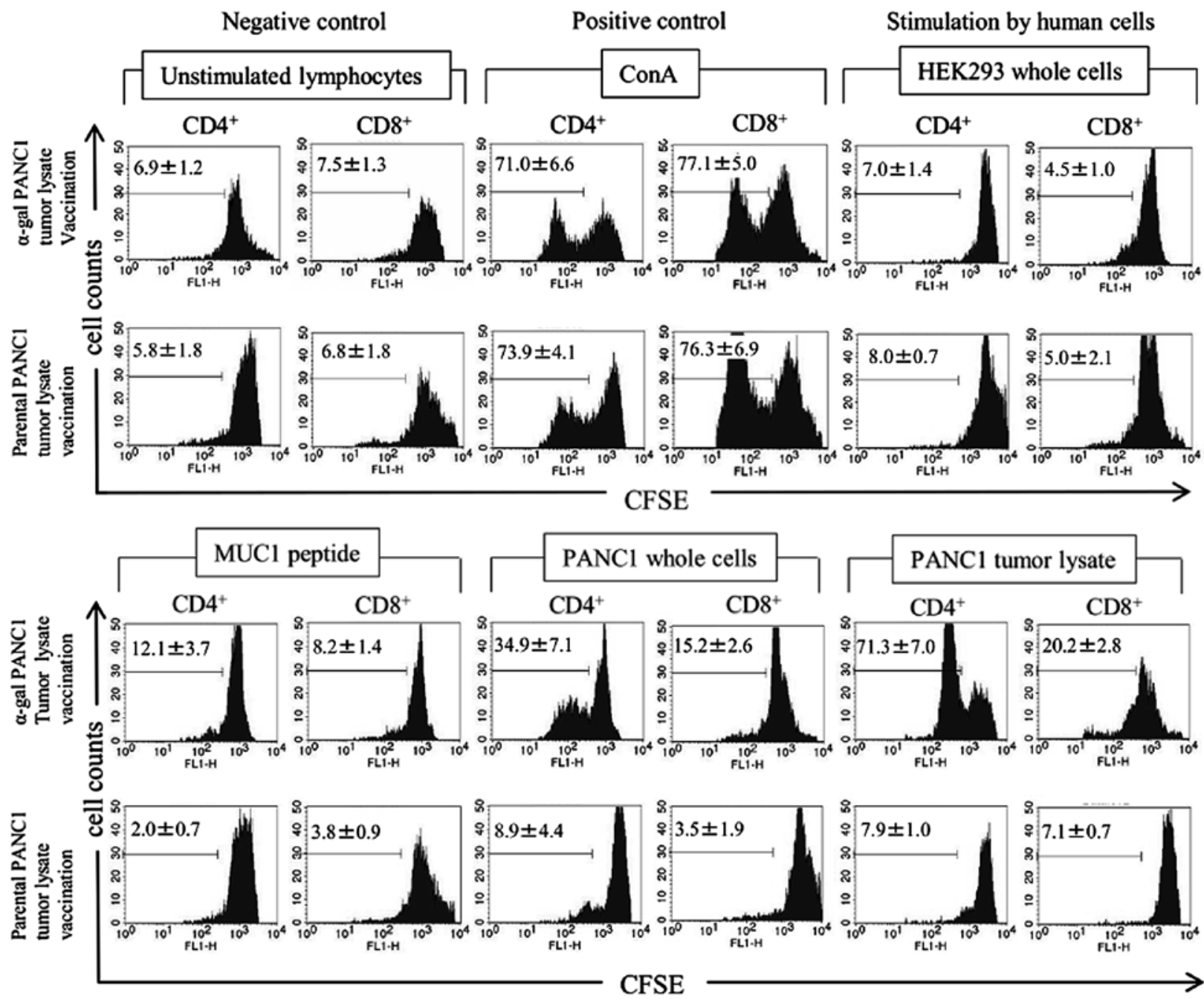

Figure 6. Specificity of immune response induced by tumor lysate vaccination, assessed by the CFSE cell proliferation assay. Histograms of CD4 ${ }^{+}$and CD8 ${ }^{+}$ proliferated T cells, which are displayed as CFSE-low responder T cells. The number in the left upper corner of the histograms represent the mean \pm SD of the percentage of $\mathrm{CD}^{+}$and $\mathrm{CD}^{+}$proliferated T cells. Data are the mean $\pm \mathrm{SD}$ of five independent experiments (MUC1 peptide stimulation: MUC1 responder $\mathrm{CD} 4^{+} \mathrm{T}$ cells, $\alpha$-gal vs. parental: $\mathrm{P}=0.010$; MUC1 responder $\mathrm{CD} 8^{+} \mathrm{T}$ cells, $\alpha$-gal vs. parental: $\mathrm{P}=0.011$; PANC1 whole cell stimulation: PANC1 whole cell responder $\mathrm{CD} 4^{+} \mathrm{T}$ cells, $\alpha$-gal vs. parental: $\mathrm{P}=0.048$; $\mathrm{PANC} 1$ whole cell responder $\mathrm{CD} 8^{+} \mathrm{T}$ cells, $\alpha$-gal vs. parental: $\mathrm{P}=0.036$; $\mathrm{PANC1}$ tumor lysate stimulation: PANC1 tumor lysate responder $\mathrm{CD} 4^{+} \mathrm{T}$ cells, $\alpha$-gal vs. parental: $\mathrm{P}=0.0001$; $\mathrm{PANC} 1$ tumor lysate responder $\mathrm{CD} 8^{+} \mathrm{T}$ cells, $\alpha$-gal vs. parental: $\left.\mathrm{P}=0.0014\right)$.

Table I. The in vivo antitumor response against live parental PANC1 cells in adoptive transferred NOD/SCID mice.

\begin{tabular}{lcccc} 
Type of vaccination $(\mathrm{n})$ & $\begin{array}{c}\text { Control mice } \\
(\text { no vaccination) }(\mathrm{n}=10)\end{array}$ & $\begin{array}{c}\text { Parental PANC1 } \\
\text { tumor lysate }(\mathrm{n}=10)\end{array}$ & $\begin{array}{c}\alpha \text {-gal PANC1 } \\
\text { whole cell }(\mathrm{n}=5)\end{array}$ & $\begin{array}{c}\alpha \text {-gal PANC1 } \\
\text { tumor lysate }(\mathrm{n}=10)\end{array}$ \\
\hline Time to appearance & $10.6 \pm 2.5^{\mathrm{a}, \mathrm{b}}$ & $11.9 \pm 2.1^{\mathrm{c}}$ & $16.0 \pm 2.8$ & No tumor formation
\end{tabular}

of a palpable tumor

(Mean \pm SD, days)

Time to tumor size

$31.4 \pm 2.1^{\mathrm{d}, \mathrm{e}}$

$40.3 \pm 6.9^{\mathrm{f}}$

$45.6 \pm 8.3$

No tumor formation

reaching $100 \mathrm{~mm}^{2}$

(Mean \pm SD, days)

Mean survival time

$41.0 \pm 5.7^{\mathrm{g}, \mathrm{h}, \mathrm{i}}$

$48.0 \pm 6.7^{\mathrm{j}, \mathrm{k}}$

$57.0 \pm 12.6$

$82.5 \pm 21.9$

(Mean \pm SD, days)

Data are expressed as the mean \pm SD from 10 or 5 independent experiments. N.S., not significant. ${ }^{a}$ N.S. vs. the parental PANC1 tumor lysate; ${ }^{\mathrm{b}} \mathrm{P}=0.018$ vs. the $\alpha$-gal $\mathrm{PANC} 1$ whole cell; ${ }^{\mathrm{C}} \mathrm{P}=0.004$ vs. the $\alpha$-gal $\mathrm{PANC} 1$ whole cell; ${ }^{\mathrm{d}} \mathrm{P}=0.007$ vs. the parental $\mathrm{PANC} 1$ tumor lysate; ${ }^{\mathrm{e}} \mathrm{P}=0.0013$ vs. the $\alpha$-gal PANC1 whole cell; ${ }^{\mathrm{f}} \mathrm{N}$.S. vs. the $\alpha$-gal PANC1 whole cell; ${ }^{\mathrm{g}} \mathrm{P}=0.02$ vs. the parental PANC1 tumor lysate; ${ }^{\mathrm{h}} \mathrm{P}=0.0077$ vs. the $\alpha$-gal PANC1 whole cell; ${ }^{i} \mathrm{P}<0.001$ vs. the $\alpha$-gal PANC1 tumor lysate; ${ }^{\mathrm{N}} \mathrm{S} . \mathrm{S}$. vs. the $\alpha$-gal PANC1 whole cell; ${ }^{\mathrm{k}} \mathrm{P}<0.001$ vs. the $\alpha$-gal PANC1 tumor lysate; ${ }^{1} \mathrm{P}=0.01$ vs. the $\alpha$-gal PANC1 tumor lysate. 
A
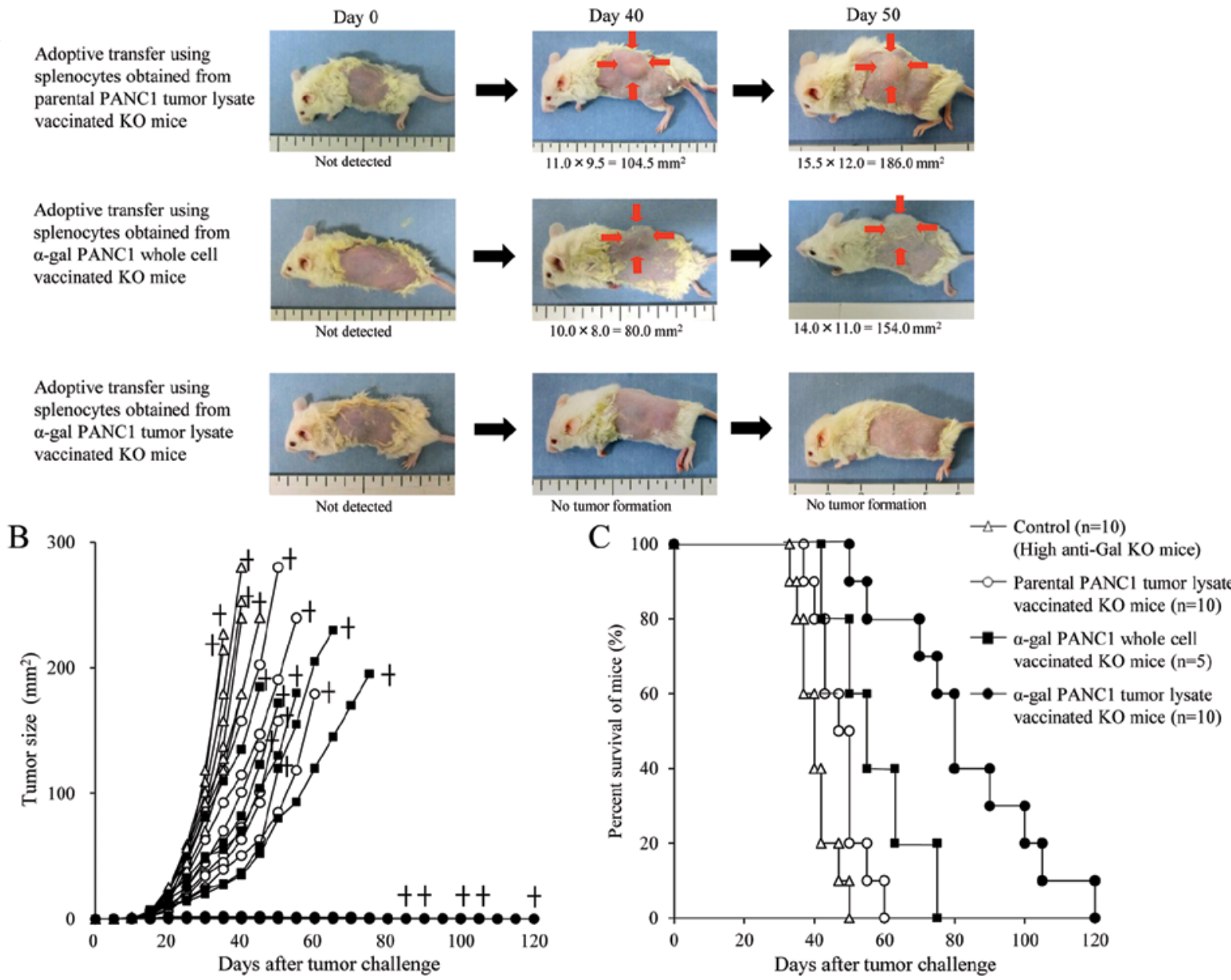

Figure 7. In vivo tumor growth and survival of the adoptive transfer NOD/SCID mice challenged by live PANC1 cells. (A) Photographs of the adoptive transfer NOD/SCID mice after tumor cell challenge with live PANC1 cells. (B) Size of subcutaneous tumors after challenge with live PANC1 cells; +: death. The tumor sizes of five individual recipients in each group after adoptive transfer are shown. (C) Survival curves of the adoptive transfer NOD/SCID mice after tumor cell challenge with live PANC1 cells. The curves were generated by the Kaplan-Meier method and assessed by the log-rank test.

pt-lysate-vaccinated and $\alpha$-gal-whole-c-vaccinated KO mice were indicated as cancer death, whereas mice transferred from $\alpha$-gal-t-lysate-vaccinated $\mathrm{KO}$ mice died a natural death without the appearance of cancer. Notably, the mean survival time was significantly improved in the pt-lysate-vaccinated group compared with the non-vaccinated group $(\mathrm{P}=0.02)$, despite the lack of synthesis of $\alpha$-gal epitopes in the tumor lysate vaccine.

a-gal PANC1 tumor lysate vaccine protects and prolongs survival of NOD/SCID mice harboring pancreatic cancer stem cell tumors. Compared with untreated control mice (data not shown), pt-lysate- or $\alpha$-gal-whole-c-vaccinated mice developed large tumors, but the tumorigenesis of pancreatic CSCs was completely prevented in all $\alpha$-gal-t-lysate-vaccinated mice (Fig. 8A and B). With the exception of the $\alpha$-gal-t-lysate group, there were no significant differences in the time to appearance of palpable tumors after tumor challenge among the groups (untreated, 13.1 \pm 3.3 days; pt-lysate, $14.4 \pm 3.4$ days; $\alpha$-galwhole-c, 17.0 \pm 3.8 days) (Table II). The tumor size reached $100 \mathrm{~mm}^{2}$ in $40.6 \pm 1.8$ and $48.0 \pm 4.4$ days in the untreated and pt-lysate groups, respectively; while, tumor growth to a similar size was significantly delayed in the $\alpha$-gal-whole-c group, (60.5 \pm 7.9 days; $\mathrm{P}<0.001$, vs. control; $\mathrm{P}=0.033$, vs. pt-lysate)
(Fig. 8B, Table II). However, vaccination with pt-lysate and $\alpha$-gal-whole-c did not prolong the survival time after tumor challenge $(49.3 \pm 14.3$ and $60.0 \pm 16.8$ days, respectively), compared with the non-vaccinated control mice $(46.5 \pm 11.8$ days) (Fig. 8C, Table II). The final causes of death for these mice were indicated as cancer death. In contrast, vaccination using $\alpha$-gal-t-lysate significantly improved survival after tumor challenge and these treated mice died a natural death without the appearance of cancer $(85.0 \pm 20.8$ days; $\mathrm{P}<0.001$ vs. control; $\mathrm{P}=0.002$ vs. pt-lysate; $\mathrm{P}=0.018$ vs. $\alpha$-gal-whole-c) (Fig. 8C, Table II). The mean survival time was not significantly different between mice vaccinated with pt-lysate and the non-vaccinated control group (Fig. 8C, Table II), despite the beneficial effects seen with live parental PANC1 cells.

Vaccination with $\alpha$-gal PANC1 tumor lysate induces production of antibodies against parental PANCl and $C D 44^{+} C D 24^{+}$ isolated PANCl cells. As shown in Fig. 9A, sera from both the $\alpha$-gal-whole-c and $\alpha$-gal-t-lysate groups more strongly bound to CD44-CD24- PANC1 cells than those from the pt-lysate group, as judged by the mean fluorescence intensity. There was strong $\mathrm{Ab}$ production against pancreatic CSCs (i.e., $\mathrm{CD} 44^{+} \mathrm{CD} 24^{+}$isolated PANC1 cells) elicited by vaccination 
A
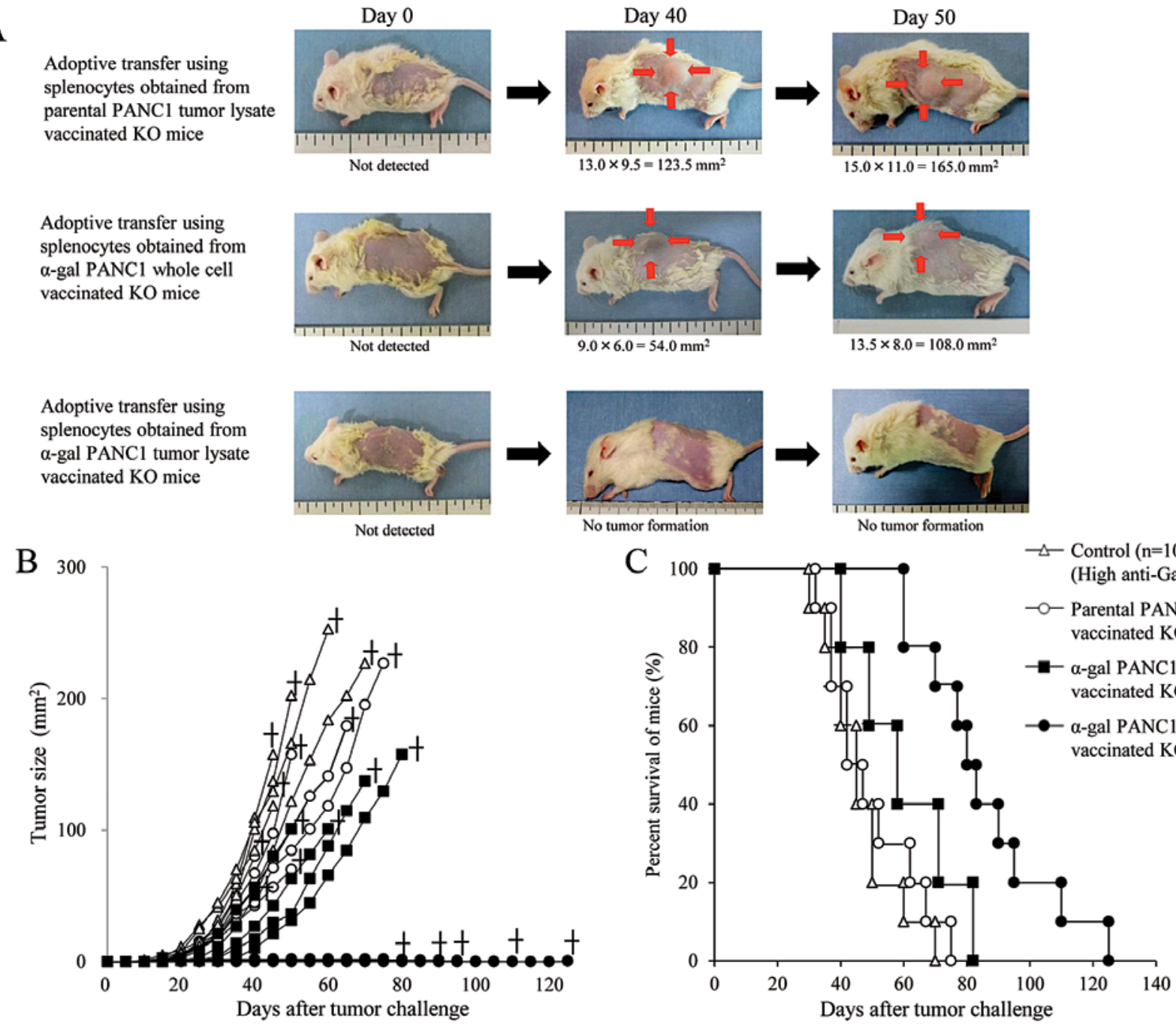

Figure 8. In vivo tumor growth and survival of the adoptive transfer NOD/SCID mice, challenged by live CD44 ${ }^{+} \mathrm{CD} 24^{+}$PANC1 cells. (A) Images of the adoptive transfer NOD/SCID mice after tumor cell challenge with live CD44 ${ }^{+} \mathrm{CD} 24^{+} \mathrm{PANC} 1$ cells. (B) Size of subcutaneous tumors after challenge with live $\mathrm{CD} 44^{+} \mathrm{CD} 24^{+} \mathrm{PANC} 1$ cells; + , death. The tumor sizes of five individual recipients in each group after adoptive transfer are shown. (C) Survival curves of the adoptive transfer NOD/SCID mice after tumor cell challenge with live CD44+CD24 ${ }^{+} \mathrm{PANC} 1$ cells.

Table II. The in vivo antitumor response against pancreatic cancer stem cells in the adoptive transfer NOD/SCID mice.

\begin{tabular}{lcccc}
\hline Type of vaccination $(\mathrm{n})$ & $\begin{array}{c}\text { Control mice } \\
\text { (no vaccination) }(\mathrm{n}=10)\end{array}$ & $\begin{array}{c}\text { Parental PANC1 } \\
\text { tumor lysate }(\mathrm{n}=10)\end{array}$ & $\begin{array}{c}\alpha \text {-gal PANC1 } \\
\text { whole cell }(\mathrm{n}=5)\end{array}$ & $\begin{array}{c}\alpha \text {-gal PANC1 } \\
\text { tumor lysate }(\mathrm{n}=10)\end{array}$ \\
\hline $\begin{array}{l}\text { Time to appearance } \\
\text { of a palpable tumor } \\
\text { (Mean } \pm \mathrm{SD} \text {, days) }\end{array}$ & $13.1 \pm 3.3^{\mathrm{a}, \mathrm{b}}$ & $14.4 \pm 3.4^{\mathrm{c}}$ & $17.0 \pm 3.8$ & No tumor formation \\
$\begin{array}{l}\text { Time to tumor size } \\
\text { reaching } 100 \mathrm{~mm}^{2} \\
\text { (Mean } \pm \mathrm{SD} \text {, days) }\end{array}$ & $40.6 \pm 1.8^{\mathrm{d}, \mathrm{e}}$ & $48.0 \pm 4.4^{\mathrm{f}}$ & $60.5 \pm 7.9$ & No tumor formation \\
$\begin{array}{l}\text { Mean survival time } \\
\text { (Mean } \pm \mathrm{SD} \text {, days) }\end{array}$ & $46.5 \pm 11.8^{\mathrm{g}, \mathrm{h}, \mathrm{i}}$ & $49.3 \pm 14.3^{\mathrm{j}, \mathrm{k}}$ & $60.0 \pm 16.8^{1}$ & $85.0 \pm 20.8$ \\
\hline
\end{tabular}

Data are expressed as the mean \pm SD from 10 or 5 independent experiments. N.S., not significant. ${ }^{a}$ N.S. vs. the parental PANC1 tumor lysate; ${ }^{b}$ N.S. vs. the $\alpha$-gal PANC1 whole cell; ${ }^{c} N . S$. vs. the $\alpha$-gal PANC1 whole cell; ${ }^{d} \mathrm{P}=0.011$ vs. the parental PANC1 tumor lysate; ${ }^{e} \mathrm{P}<0.001 \mathrm{vs}$. the $\alpha$-gal PANC1 whole cell; ${ }^{\mathrm{P}} \mathrm{P}=0.033$ vs. the $\alpha$-gal PANC1 whole cell; ${ }^{\mathrm{g}} \mathrm{N} . \mathrm{S}$. vs. the parental PANC1 tumor lysate; ${ }^{\text {h}} \mathrm{N} . \mathrm{S}$. vs. the $\alpha$-gal PANC1 whole cell; ${ }^{\mathrm{i}} \mathrm{P}<0.001$ vs. the $\alpha$-gal PANC1 tumor lysate; ${ }^{\mathrm{j} N}$.S. vs. the $\alpha$-gal PANC1 whole cell; ${ }^{\mathrm{k}} \mathrm{P}=0.002$ vs. the $\alpha$-gal PANC1 tumor lysate; ${ }^{\mathrm{l}} \mathrm{P}=0.018$ vs. the $\alpha$-gal PANC1 tumor lysate. 
A Anti-CD44-CD24- PANC1 Ab production

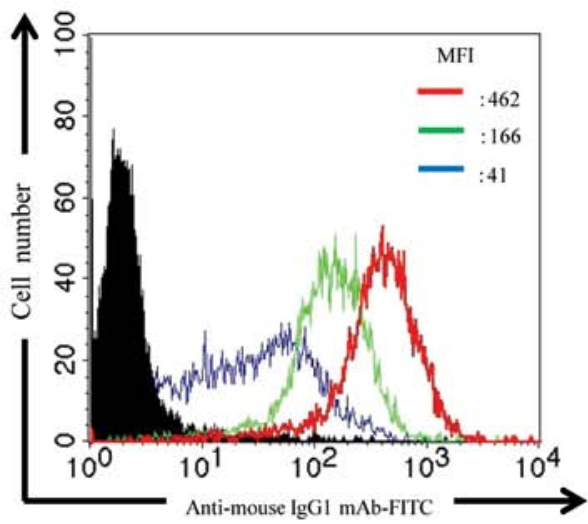

$\mathrm{C}$

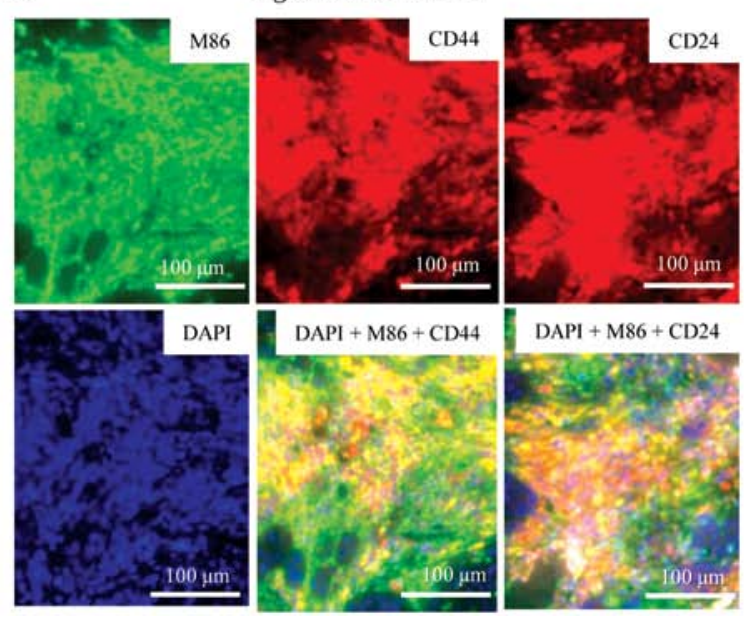

B Anti-CD44 $4^{+} \mathrm{CD}_{2} 4^{+} \mathrm{PANC1}$ Ab production

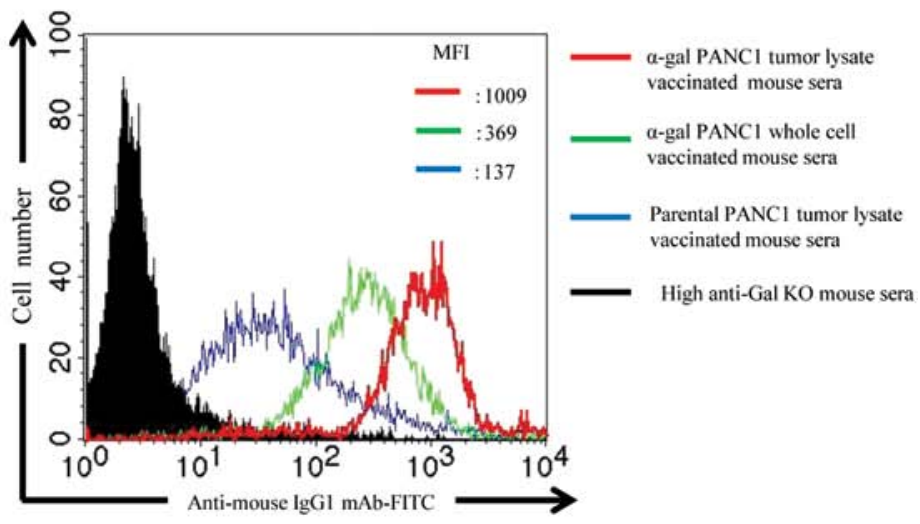

D

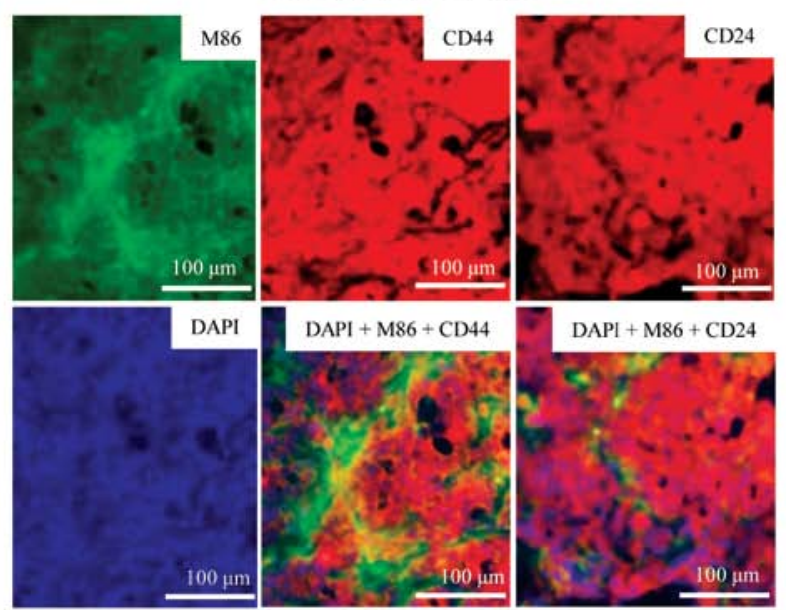

Figure 9. Production of antibodies against differentiated cancer cells and cancer stem cells and immunofluorescence findings from PANC1 tumors. (A and B) Production of antibodies in sera from vaccinated high anti-Gal KO mice: (A) anti-CD44-CD24- PANC1 Ab, (B) anti-CD44 ${ }^{+} \mathrm{CD} 24^{+}$PANC1 Ab. Representative data from five experiments with similar results are shown. (C and D) Images of tumors stained with M86, anti-CD24, or anti-CD44 mAbs; (C) $\alpha$-gal PANC1 tumors, (D) parental PANC1 tumors. Bars, $100 \mu \mathrm{m}$.

with $\alpha$-gal-whole-c and $\alpha$-gal-t-lysate (Fig. 9B). Importantly, vaccination with $\alpha$-gal-t-lysate induced better $\mathrm{Ab}$ production against both CD44-CD24- PANC1 cells and pancreatic CSCs than with $\alpha$-gal-whole-c, as judged by the mean fluorescence intensity (Fig. 9A and B).

Evaluation of $\alpha$-gal epitope expression (M86 staining) revealed there was abundant expression of $\alpha$-gal epitopes in $\alpha$-gal PANC1 tumors; whereas, expression of $\alpha$-gal epitopes was scarcely observed in parental PANC1 tumors (Fig. 9C and D). Both CD44 and CD24 molecules were expressed in $>90 \%$ of cancer cells in PANC1 tumors on NOD/SCID mice. The expression levels of these CSC markers in PANC1 tumor cells were markedly upregulated in comparison with the levels in either $\alpha$-gal or parental PANC1 cells $(12,13)$. Thus, the CSC components in PANC1 cells were enriched upon tumor formation in NOD/SCID mice. In $\alpha$-gal PANC1 tumor tissue, merged microphotographs showed tissues stained positive for both M86 and CD44 as well as for both M86 and CD24; thus, the tissues simultaneously expressed the $\alpha$-gal epitopes and CD44 or CD24 on the cell surface (Fig. 9C, yellow regions). However, no yellow regions were observed in parental PANC1 tumor tissue (Fig. 9D). These results suggest that the build- up of $\alpha$-gal epitopes on the carbohydrates of CSC-related molecules allows the internalization and antigen-presentation of these molecules by APC. Furthermore, the concentration of CSC-related molecules in the tumor lysate vaccine seems greater than in the whole cell vaccine (i.e., $\alpha$-gal PANC1 whole cell vaccine).

\section{Discussion}

The three main findings of the present study were: i) tumor lysate vaccines elicited strong antibody production against pancreatic cancer cells, the MUC1 peptide, and CD $44^{+} \mathrm{CD} 24^{+}$ PANC1 cells, and the latter were isolated as a pancreatic CSC population; ii) tumor lysate vaccination led to effective activation of T cells specific to both the MUC1 peptide and endogenous TAA molecules derived from pancreatic cancer cells; and iii) in vivo experiments on challenge with either live pancreatic cancer cells or a CD $44^{+} \mathrm{CD} 24^{+}$pancreatic CSC population demonstrated an immune response was induced that completely prevented tumor development at local sites in the adoptive transferred NOD/SCID mice. Moreover, the immune response against live tumor cells, elicited by $\alpha$-gal 
PANC1 tumor lysate vaccination, was significantly stronger than that induced by the $\alpha$-gal PANC1 whole cell vaccination.

For clinical application of this effective immunotherapy, we need to assess the toxicity and safety of injection of $\alpha$-gal tumor lysate in humans. The major concern before the start of the present study was that effective uptake of anti-Gal opsonized tumor lysate by APC might induce an immune response against both normal antigens of the tumor lysate and normal cells, such as stromal cells in the tumor. Previous clinical trials using lysate or whole cancer cells as a source of vaccine showed no clinically relevant autoimmune responses (22-24). This conclusion should be further examined in humans to verify whether there is a lack of clinical evidence of auto-immunity induced by $\alpha$-gal tumor lysate vaccination. Although we plan to primarily employ autologous tumor lysate, which is surgically resected from patients with pancreatic cancer and enzymatically processed in vitro to express $\alpha$-gal epitopes, as the vaccinating material (25), the volume of tumor mass in the resected pancreas is small and limited. Actually, the vast majority of patients are diagnosed as inoperable because they present with incurable metastatic disease. To overcome this critical situation, we propose to generate the tumors in mice to create vaccinating material, as in the present study.

Pancreatic cancer-associated antigens that are candidates for potential immune targeting include Her2/neu (26), MUC1 (27), CEA (4), mesothelin (5,24), telomerase (28) and survivin (29). However, vaccinating against a single antigen is disadvantageous because it is not known what exact antigen can potentially induce a more effective antitumor immune response. Furthermore, immunity against a single antigen may be ineffective in tumors with heterogeneous cell populations and carries the risk of inducing tumor antigen escape variants $(30,31)$. However, this strategy is sometimes applicable to those patients with a specific HLA type. To overcome the drawbacks of single antigen immunotherapy, several groups used multiple-antigen vaccine platforms and reported successful induction of antigen-specific immune responses $(32,33)$. However, these studies were conducted in animal models of tumors or in in vitro $(32,33)$. The use of unfractionated tumor-derived antigens in the form of tumor lysates circumvents these disadvantages because tumor lysates contain multiple known and unknown antigens that can be presented to T cells by both MHC class I- and class II-pathways (34-36). Therefore, effective uptake of $\alpha$-gal tumor lysate by APC is more likely to induce a polyclonal expansion of $\mathrm{T}$ cells, including MHC class II-restricted T-helper cells. These cells have been recognized to play an important role in the activation of $\mathrm{CD}^{+} \mathrm{CTLs}$, probably the most important cells in any antitumor immune response $(22,23,30)$. The generation of CTL clones with multiple specificities may be an advantage in heterogeneous tumors and could also reduce the risk of tumor escape variants.

The lethal nature of pancreatic cancer is due to the ability of remnant cells, including differentiated cancer cells and CSCs after surgery, chemotherapy and radiation therapy, to develop into recurrent or metastatic tumors. However, these remnant residual cancer cells might be destroyed by strong activation of immunocytes, induced by vaccination with the $\alpha$-gal tumor lysate that can specifically attack and destroy TAA-expressing tumor cells. The most encouraging results of immunotherapy in pancreatic cancer have been in adjuvant settings, such as post-surgery $(37,38)$. Moreover, due to genome instability and the heterogeneity in pancreatic cancer, the immunological setting for the destruction of TAA-expressing tumor cells frequently results in the appearance and expansion of tumor cell subclones with no or low expression of the specific TAA (39-41). Our previous study demonstrated the effect of using tumor cells as a vaccine source to inhibit the development of transplanted melanoma cell tumors in mice (12). However, the inhibition of tumor formation was not complete. The weakness of such vaccine therapy could be related to the use of melanoma cells rather than pancreatic cancer cells, or the use of a less than optimal vaccine therapy to overcome various types of CSCs due to the presence of only a few TAAs in the whole cell vaccine. To achieve complete destruction of CSCs, it may be necessary to target the tumor microenvironment as well as tumor cells themselves. For this purpose, tumor tissue lysate seems to offer a better option than tumor cell lysate as a source of vaccine. A polyvalent tumor lysate vaccine, engineered to express $\alpha$-gal epitopes and prepared from autologous tumors, is the most suitable material for immunotherapy. Notably, recent studies demonstrated that the heterogeneity of metastases reflects heterogeneity already existing within the primary tumor, and that the primary carcinoma is a mixture of numerous subclones, each of which independently expands to form a large number of cells $(42,43)$.

In summary, we plan to employ autologous tumor lysate prepared from surgically resected pancreas cancer, which is enzymatically processed in vitro to express $\alpha$-gal epitopes, as vaccinating material; although, the tumor mass in the resected pancreas is often small and limited. The vast majority of patients are diagnosed as inoperable because they present with incurable metastatic disease. To overcome this problem, we propose using tumors generated in mice as candidate vaccination material. We hope that the use of a tumor lysate vaccine, engineered to express $\alpha$-gal epitopes, can elicit a strong immune response toward all pancreatic cancer cells, including differentiated pancreatic cancer cells and pancreatic CSCs, and may improve the prognosis for patients with pancreatic cancer.

\section{Acknowledgements}

The authors thank Professor Uri Galili from the University of Massachusetts Medical School (Worcester, MA) for generously providing $\alpha 1,3 \mathrm{GT}$ KO mice, and Dr Haruko Ogawa from Obihiro University of Agriculture and Veterinary Medicine (Obihiro, Hokkaido) for generously providing plasmids encoding the murine $\alpha 1,3 \mathrm{GT}$ gene. The authors thank Dr Paul Kretchmer, (San Francisco Edit, CA, USA) for the careful reading and editing of the manuscript. The present study was supported by a grant from the Ministry of Education, Sports, and Culture of Japan to Masahiro Tanemura (no. 22591520). The study was also supported in part by a Takamatsuno-miya cancer grant to Eiji Miyoshi (no. 27324).

\section{References}

1. Jemal A, Bray F, Center MM, Ferlay J, Ward E and Forman D: Global cancer statistics. CA Cancer J Clin 61: 69-90, 2011. 
2. Lepisto AJ, Moser AJ, Zeh H, et al: A phase I/II study of a MUC1 peptide pulsed autologous dendritic cell vaccine as adjuvant therapy in patients with resected pancreatic and biliary tumors. Cancer Ther 6: 955-964, 2008.

3. Gjertsen MK, Bakka A, Breivik J, et al: Vaccination with mutant ras peptides and induction of T-cell responsiveness in pancreatic carcinoma patients carrying the corresponding RAS mutation. Lancet 346: 1399-1400, 1995.

4. Laheru D and Jaffee EM: Immunotherapy for pancreatic cancer - science driving clinical progress. Nat Rev Cancer 5: 459-467, 2005.

5. Argani P, Iacobuzio-Donahue C, Ryu B, et al: Mesothelin is overexpressed in the vast majority of ductal adenocarcinomas of the pancreas: identification of a new pancreatic cancer marker by serial analysis of gene expression (SAGE). Clin Cancer Res 7 : 3862-3868, 2001.

6. Liyanage UK, Moore TT, Joo HG, et al: Prevalence of regulatory $\mathrm{T}$ cells is increased in peripheral blood and tumor microenvironment of patients with pancreas or breast adenocarcinoma. J Immunol 169: 2756-2761, 2002.

7. Soares KC, Zheng L, Edil B and Jaffee EM: Vaccines for pancreatic cancer. Cancer J 18: 642-652, 2012

8. Galili U, Clark MR, Shohet SB, Buehler J and Macher BA: Evolutionary relationship between the natural anti-Gal antibody and the Gal alpha $1 \rightarrow 3 \mathrm{Gal}$ epitope in primates. Proc Natl Acad Sci USA 84: 1369-1373, 1987.

9. Tanemura M, Yin D, Chong AS and Galili U: Differential immune responses to alpha-gal epitopes on xenografts and allografts: implications for accommodation in xenotransplantation. J Clin Invest 105: 301-310, 2000.

10. Tanemura M, Saga A, Kawamoto K, et al: In vitro and in vivo prevention of human $\mathrm{CD} 8^{+} \mathrm{CTL}-$ mediated xenocytotoxicity by pig c-FLIP expression in porcine endothelial cells. Am J Transplant 8: 288-297, 2008.

11. Galili U and LaTemple DC: Natural anti-Gal antibody as a universal augmenter of autologous tumor vaccine immunogenicity. Immunol Today 18: 281-285, 1997.

12. Deguchi T, Tanemura M, Miyoshi E, et al: Increased immunogenicity of tumor-associated antigen, mucin 1, engineered to express alpha-gal epitopes: a novel approach to immunotherapy in pancreatic cancer. Cancer Res 70: 5259-5269, 2010.

13. Wang Z, Li Y, Ahmad A, et al: Pancreatic cancer: understanding and overcoming chemoresistance. Nat Rev Gastroenterol Hepatol 8: 27-33, 2011

14. Li C, Heidt DG, Dalerba P, et al: Identification of pancreatic cancer stem cells. Cancer Res 67: 1030-1037, 2007.

15. LaTemple DC and Galili U: Adult and neonatal anti-Gal response in knock-out mice for alpha1,3-galactosyltransferase. Xenotransplantation 5: 191-196, 1998.

16. Thall AD, Maly P and Lowe JB: Oocyte Gal alpha $1,3 \mathrm{Gal}$ epitopes implicated in sperm adhesion to the zona pellucida glycoprotein $\mathrm{ZP} 3$ are not required for fertilization in the mouse. J Biol Chem 270: 21437-21440, 1995.

17. Sipos B, Moser S, Kalthoff H, Torok V, Lohr M and Kloppel G: A comprehensive characterization of pancreatic ductal carcinoma cell lines: towards the establishment of an in vitro research platform. Virchows Arch 442: 444-452, 2003.

18. LaTemple DC, Henion TR, Anaraki F and Galili U: Synthesis of alpha-galactosyl epitopes by recombinant alpha1,3galactosyl transferase for opsonization of human tumor cell vaccines by anti-galactose. Cancer Res 56: 3069-3074, 1996.

19. Tanemura M, Maruyama S and Galili U: Differential expression of alpha-GAL epitopes (Galalpha1-3Galbeta1-4GlcNAc-R) on pig and mouse organs. Transplantation 69: 187-190, 2000.

20. Kawamoto K, Tanemura M, Nishida T, Fukuzawa M, Ito T and Matsuda H: Significant inhibition of human CD8(+) cytotoxic T lymphocyte-mediated xenocytotoxicity by overexpression of the human decoy Fas antigen. Transplantation 81: 789-796, 2006.

21. LaTemple DC, Abrams JT, Zhang SY and Galili U: Increased immunogenicity of tumor vaccines complexed with anti-Gal: studies in knockout mice for alpha1,3-galactosyltransferase. Cancer Res 59: 3417-3423, 1999.
22. Thomas AM, Santarsiero LM, Lutz ER, et al: Mesothelin-specific $\mathrm{CD} 8^{+} \mathrm{T}$ cell responses provide evidence of in vivo cross-priming by antigen-presenting cells in vaccinated pancreatic cancer patients. J Exp Med 200: 297-306, 2004.

23. Jaffee EM, Hruban RH, Biedrzycki B, et al: Novel allogeneic granulocyte-macrophage colony-stimulating factor-secreting tumor vaccine for pancreatic cancer: a phase I trial of safety and immune activation. J Clin Oncol 19: 145-156, 2001.

24. Hassan R and Ho M: Mesothelin targeted cancer immunotherapy. Eur J Cancer 44: 46-53, 2008.

25. Galili U, Chen ZC and DeGeest K: Expression of alpha-gal epitopes on ovarian carcinoma membranes to be used as a novel autologous tumor vaccine. Gynecol Oncol 90: 100-108, 2003.

26. Ladjemi MZ, Jacot W, Chardes T, Pelegrin A and NavarroTeulon I: Anti-HER2 vaccines: new prospects for breast cancer therapy. Cancer Immunol Immunother 59: 1295-1312, 2010.

27. Tang CK, Katsara M and Apostolopoulos V: Strategies used for MUC1 immunotherapy: human clinical studies. Expert Rev Vaccines 7: 963-975, 2008

28. Liu JP, Chen W, Schwarer AP and Li H: Telomerase in cancer immunotherapy. Biochim Biophys Acta 1805: 35-42, 2010.

29. Ryan BM, O'Donovan N and Duffy MJ: Survivin: a new target for anti-cancer therapy. Cancer Treat Rev 35: 553-562, 2009.

30. Saito H, Dubsky P, Dantin C, Finn OJ, Banchereau J and Palucka AK: Cross-priming of cyclin B1, MUC-1 and survivinspecific $\mathrm{CD}^{+} \mathrm{T}$ cells by dendritic cells loaded with killed allogeneic breast cancer cells. Breast Cancer Res 8: R65, 2006.

31. Schnurr M, Scholz C, Rothenfusser S, et al: Apoptotic pancreatic tumor cells are superior to cell lysates in promoting crosspriming of cytotoxic T cells and activate NK and gammadelta T cells. Cancer Res 62: 2347-2352, 2002.

32. Bohnenkamp HR, Coleman J, Burchell JM, TaylorPapadimitriou J and Noll T: Breast carcinoma cell lysate-pulsed dendritic cells cross-prime MUC1-specific $\mathrm{CD}^{+} \mathrm{T}$ cells identified by peptide-MHC-class-I tetramers. Cell Immunol 231: $112-125,2004$.

33. Palucka AK, Ueno H, Connolly J, et al: Dendritic cells loaded with killed allogeneic melanoma cells can induce objective clinical responses and MART-1 specific $\mathrm{CD} 8^{+}$T-cell immunity. J Immunother 29: 545-557, 2006.

34. Fields RC, Shimizu K and Mule JJ: Murine dendritic cells pulsed with whole tumor lysates mediate potent antitumor immune responses in vitro and in vivo. Proc Natl Acad Sci USA 95: 9482-9487, 1998

35. Brossart P and Bevan MJ: Presentation of exogenous protein antigens on major histocompatibility complex class I molecules by dendritic cells: pathway of presentation and regulation by cytokines. Blood 90: 1594-1599, 1997.

36. Shen Z, Reznikoff G, Dranoff G and Rock KL: Cloned dendritic cells can present exogenous antigens on both MHC class I and class II molecules. J Immunol 158: 2723-2730, 1997.

37. Shakhar G and Ben-Eliyahu S: Potential prophylactic measures against postoperative immunosuppression: could they reduce recurrence rates in oncological patients? Ann Surg Oncol 10: 972-992, 2003.

38. Weighardt H, Heidecke CD, Emmanuilidis K, et al: Sepsis after major visceral surgery is associated with sustained and interferon-gamma-resistant defects of monocyte cytokine production. Surgery 127: 309-315, 2000.

39. Livingston P: The unfulfilled promise of melanoma vaccines. Clin Cancer Res 7: 1837-1838, 2001

40. Khong HT and Restifo NP: Natural selection of tumor variants in the generation of 'tumor escape' phenotypes. Nat Immunol 3: 999-1005, 2002.

41. Dunn GP, Bruce AT, Ikeda H, Old LJ and Schreiber RD: Cancer immunoediting: from immunosurveillance to tumor escape. Nat Immunol 3: 991-998, 2002.

42. Campbell PJ, Yachida S, Mudie LJ, et al: The patterns and dynamics of genomic instability in metastatic pancreatic cancer. Nature 467: 1109-1113, 2010

43. Yachida S, Jones S, Bozic I, et al: Distant metastasis occurs late during the genetic evolution of pancreatic cancer. Nature 467 : 1114-1117, 2010. 